\title{
Analisis Faktor Penerapan Budaya Sasaran Keselamatan Pasien di Rumah Sakit : A Literature Review
}

\author{
Amalia Mastuty $^{1)^{*}}$, Haris Suhamdani1 ${ }^{1)}$, Vera Yulandasari ${ }^{1)}$, Teguh Achmalona ${ }^{1)}$ \\ Email: amaliamastuty99@gmail.com
}

${ }^{1)}$ Prodi KeperawatanUniversitas Qamarul Huda Badaruddin Bagu

\begin{abstract}
ABSTRAK
Sasaran keselamatan pasien (SKP) menjadi isu global dalam pelayanan kesehatan di rumah sakit dan memerlukan perhatian khusus dalam pelaksanaannya. Tujuan dari kajian ini adalah untuk mengidentifikasi faktor-faktor yang berpengaruh terhadap penerapan SKP. Kata kunci yang digunakan, yaitu: patient safety, health, health worker, Pencarian artikel jurnal dilakukan secara elektronik dengan menggunakan beberapa database, yaitu: Proquest, Google Scholar, Science Direct. Batasan waktu yang digunakan adalah Januari 2009 hingga Desember 2019. Dari 1812 artikel yang diperoleh 16 artikel yang memenuhi kriteria inklusi. Dari 16 literatur tersebut telah diperoleh faktor-faktor yang mempengaruhi penerapan SKP antara lain, aspek ekonomi, kepemimpinan, budaya, sistem pelayanan kesehatan, pengetahuan, sikap, dan tindakan tenaga professional, analisis situasi dan kondisi tempat kerja, sistem manajemen risiko, durasi jam kerja perawat, program mentoring, supervisi keperawatan, dan evaluasi penerapan SKP. Faktor-faktor tersebut dapat memberikan dukungan positif di rumah sakit untuk menerapkan sistem manajemen dan pelayanan kesehatan yang prima dengan memaksimalkan penerapan SKP sehingga dapat menekan risiko terjadinya malpraktik atau kejadian tidak diinginkan. Dalam proses penerapan SKP ini diharapkan ada kerjasama dan kolaborasi yang baik dari seluruh elemen rumah sakit agar bisa berjalan secara optimal dan memberikan dampak positif terhadap peningkatan kualitas pelayanan kesehatan.
\end{abstract}

Kata kunci: Sasaran Keselamatan Pasien, Kesehatan, Tenaga Kesehatan, A literature review

\begin{abstract}
Patient safety is a global issue of health care in hospitals and require special attention in its implementation. The purpose of this study is to identify the factors that affect the implementation of the patient safety. By using the keyword: patient safety, health, health worker, and systematic review. Journal searching in this article use multiple databases, namely: Proquest, Google Scholar, Science Direct. The duration of time in January 2009 to December 2019. From 1812 article, only 16 articles that suitable with the inclusion criteria. From the 16 literature has been acquired factors that affect the application of patient safety among others, economic aspects, leadership, culture, health care systems, knowledge, attitudes, and actions of professionals, analysis of the situation and workplace conditions, the risk management system, the duration of working hours nurses, mentoring programs, nursing supervision, and evaluation of the patient safety implementation. These factors can provide positive support in the hospital to implement a management system and excellent health services by maximizing the application of patient safety to reduce the risk of malpractice or undesirable events. In the process of implementing this patient safety expected to have good cooperation and collaboration of all elements of the hospital to be run optimally and provide a positive impact on improving the quality of health services.
\end{abstract}

Keywords: Patient Safety, Health, Health Worker, A Literature Review

A. LATAR BELAKANG

Rumah sakit mempunyai peranan penting dalam mewujudkan derajat kesehatan masyarakat secara optimal. Oleh karena itu 
rumah sakit dituntut agar mampu mengelola kegiatannya dengan mengutamakan pada tanggung jawab para professional di bidang kesehatan, khususnya tenaga medis dan tenaga keperawatan dalam menjalankan tugas dan kewenangannya. Tidak selamanya layanan medis yang diberikan oleh tenaga kesehatan dapat memberikan hasil yang sebagaimana diharapkan semua pihak. Tenaga kesehatan yang melakukan kelalaian dapat disebut melakukan malpraktik. Karena banyaknya kasus malpraktik, maka harus diterapkan program keselamatan pasien (Patient Safety).

Keselamatan menjadi isu global dan terangkum dalam lima isu penting yang terkait di rumah sakit yaitu: keselamatan pasien (patient safety), keselamatan pekerja atau petugas kesehatan, keselamatan bangunan dan peralatan di rumah sakit yang bisa berdampak terhadap keselamatan pasien dan petugas, keselamatan lingkungan (green productivity) yang berdampak terhadap pencemaran lingkungan dan keselamatan "bisnis" rumah sakit yang terkait dengan kelangsungan hidup rumah sakit. Lima aspek keselamatan tersebut penting untuk dilaksanakan, namun harus diakui kegiatan institusi rumah sakit dapat berjalan apabila ada pasien. Keselamatan pasien merupakan prioritas utama untuk dilaksanakan terkait dengan isu mutu dan citra perumahsakitan ${ }^{[1]}$. WHO (World Health Organitation) tahun 2004 mengumpulkan angka-angka penelitian rumah sakit di berbagai Negara yaitu Amerika, Inggris, Denmark dan Australia dan ditemukan KTD (Kejadian Tidak Diharapkan) dengan rentang 3,2\%-16,6\%. Data tersebut menjadi pemicu diberbagai negara untuk melakukan penelitian dan pengembangan sistem keselamatan pasien ${ }^{[1]}$.

Fenomena insiden keselamatan pasien di Indonesia masih sering terjadi hingga tahun 2015, seperti yang telah dimuat pada Kompas harian tentang sederet insiden keselamatan pasien seperti yang terjadi pada pasien An. Marthin (7th) meninggal setelah menerima perawatan luka pasca kecelakaan di RS Kefamenanu, By Adira (12hr) bengkak dan luka terbuka pada kaki bekas tindakan injeksi di RS Citama Bogor, Ny Sutiah (43th) mengalami gatal-gatal dan kedua kaki membengkak serta melepuh pasca operasi Hernia di RS Kasih Ibu Aceh Utara dan masih banyak lagi insiden keselamatan pasien yang lainnya. Hal ini menggambarkan bahwa budaya keselamatan pasien dalam pelayanan kesehatan di rumah sakit memerlukan perhatian khusus dalam pelaksanaannya, meskipun keselamatan pasien sudah menjadi harga mati bagi Rumah Sakit, namun pelaksanaanya belum semaksimal mungkin.

Perawat merupakan tenaga kesehatan yang mempunyai peranan sangat penting terhadap proses pemberian pelayanan kesehatan kepada pasien. Perawat berusaha mempertahankan dan meningkatkan kesehatan klien serta memberikan informasi pelayanan kesehatan yang jelas dan mudah dipahami oleh klien dan keluarga selama menjalani perawatan di rumah sakit. Dalam hal ini tindakan keperawatan yang tidak sesuai SPO akan berisiko terhadap menurunnya optimalisasi penerapan sasaran keselamatan pasien (SKP).

Berdasarkan fenomena tersebut, maka penulis tertarik untuk melakukan analisis lebih lanjut terkait faktor-faktor yang mempengaruhi penerapan SKP di rumah sakit.

\section{B. METODE PENELITIAN}

Pencarian literatur dilakukan di beberapa database mayor seperti PROQUEST, SCIENCEDIRECT dan GOOGLE SCHOLAR dengan memasukkan kata kunci patient safety, health, health worker. Batasan waktu yang digunakan adalah Januari 2009 hingga Desember 2019. Dari 1812 artikel yang diperoleh 16 artikel yang memenuhi kriteria inklusi. Kriteria inklusi artikel adalah: 1) variabel faktor yang mempengaruhi SKP, 2) sampel adalah tenaga kesehatan di rumah sakit, dan 3) parameter yang dinilai adalah intensitas penerapan SKP.

Dari 16 literatur tersebut telah diperoleh faktor-faktor yang mempengaruhi penerapan SKP antara lain, aspek ekonomi, kepemimpinan, budaya, sistem pelayanan kesehatan, 
pengetahuan, sikap, dan tindakan tenaga professional, analisis situasi dan kondisi tempat kerja, sistem manajemen risiko, durasi jam kerja perawat, program mentoring, supervisi keperawatan, dan evaluasi penerapan SKP. Sedangkan parameter yang digunakan untuk mengukur penerapan SKP diperoleh datanya dari instrument kuesioner, lembar observasi checklist, dan lembar interview. Jenis instrument yang sering digunakan yaitu The Practice Environmental Scale of the Nursing Work Index (PES-NWI) dan The Hospital Survey of Patient Safety Culture.

\section{HASIL DAN PEMBAHASAN}

Berdasarkan hasil telaah, didapatkan 9 faktor yang mempengaruhi penerapan SKP: antara lain 1) aspek ekonomi, 2) kepemimpinan, 3) budaya, 4) sistem manajemen risiko dan pelayanan kesehatan, 5) pengetahuan, sikap, dan tindakan, 6) analisis situasi dan kondisi lingkungan kerja, 7) durasi jam kerja perawat, 8) program mentoring, dan 9) supervisi keperawatan, dan evaluasi penerapan SKP.

\section{Aspek Ekonomi}

Penelitian dari T. Jackson et all, 2009 ${ }^{[2]}$ menunjukkan pengaruh aspek ekonomi terhadap penerapan SKP. Hasil penelitian dalam jurnal ini menunjukkan bahwa tipe penyakit terbanyak yang diperoleh dalam penelitian ini yaitu dengan gangguan endokrin dan metabolic. Dengan prosentase $17,1 \%$ pasien tersebut berasal dari kelas ekonomi menengah ke bawah yang mengalami infeksi nosocomial karena penerapan budaya SKP di rumah sakit. Dalam hal ini aspek ekonomi mempengaruhi kelas perawatan yang berhubungan dengan ketersediaan sarana dan fasilitas yang akan menunjang pelayanan kesehatan dan kenyamanan pasien selama dirawat di rumah sakit.

\section{Kepemimpinan}

Terdapat dua penelitian yang berhubungan dengan aspek kepemimpinan yang berpengaruh terhadaap penerapan SKP. Penelitian pertama, Olive Kessler, et all. $2014^{[3]}$ bertujuan untuk mengevaluasi teori, model, dan bukti empiris terhadap fungsi, aturan dan kemandirian kepemimpinan, budaya keselamatan, dan keselamatan pasien di rumah sakit. Hasil penelitian ini yaitu pengembangan kerangka kerja berdasarkan EBN yang menentukan hubungan antara kepemimpinan, budaya keselamatan, dan keselamatan pasien.

Penelitian kedua, Dwi Setiowati, et all, $2013^{[4]}$ bertujuan untuk mengetahui hubungan kepemimpinan efektif head nurse dengan penerapan budaya keselamatan pasien. Hasil analisis menunjukkan hubungan lemah dan positif antara kepemimpinan efektif Head Nurse dengan penerapan budaya keselamatan pasien. Gaya kepemimpinan efektif head nurse meliputi, kepemimpinan efektif, pengetahuan, kesadaran diri, komunikasi, penggunaan energy, penentuan tujuan, dan pengambilan tindakan.

Dalam hal ini gaya kepemimpinan memiliki pengaruh yang besar terhadap penerapan SKP. Pemimpin yang baik akan menjadi role model untuk bekerjasama dengan staffnya dalam proses penerapan SKP sehingga dapat meningkatkan kualitas pelayanan kesehatan.

\section{Budaya}

Penelitian dari N. Bouafia et all. 2015 bertujuan untuk mengetahui tingkat kepatuhan staff terhadap penerapan budaya SKP di RS Pusat Pendidikan Tunisia. Hasil penelitian ini menunjukkan bahwa 68,8 \% tenaga kesehatan menyatakan telah melakukan penerapan budaya SKP dengan baik dan $32,7 \%$ menyatakan kurangnya dukungan manajemen terhadap penerapan budaya SKP. Faktor budaya sangat mempengaruhi penerapan budaya SKP, karena keunikan karakter pemberi dan pengguna layanan kesehatan. Dalam hal ini diperlukan manajemen dan kerjasama yang baik antar staff di rumah sakit serta upaya yang penting untuk mensosialisasikan program SKP kepada seluruh warga rumah sakit baik kepada seluruh staff maupun pasien dan keluarganya

\section{Sistem Manajemen Risiko dan Pelayanan Kesehatan}

Terdapat tiga penelitian yang berhubungan dengan sistem manajemen risiko dan pelayanan 
kesehatan yang berpengaruh terhadap penerapan SKP. Penelitian pertama dari EN Dunia, et all $2015^{[6]}$ menunjukkan hasil bahwa $90 \%$ staf tenaga kesehatan di Kinshasa mengetahui manajemen risiko pengendalian infeksi dan $89 \%$ masih belum mengetahui tentang SKP. Kemudian penelitian kedua dari OA Oyourou dan M. Adeoti, 2013 ${ }^{[7]}$ menunjukkan prosentase pengaruh aspek manajemen pelayanan sebagai berikut: pengembangan kepemimpinan (64\%), kelengakapan dokumen SKP dan manajemen risiko (60\%), teknologi kesehatan (63,6\%), SDM (42\%), informasi kesehatan (40\%), evaluasi praktek perawatan (20\%), keuangan (16\%), dan penelitian kesehatan (33\%). Penelitian ketiga dari H Djibo et all, 2013 ${ }^{[8]}$ tentang pengaruh manajemen risiko terhadap penerapan SKP menunjukkan hasil sebagai berikut: $60 \%$ tenaga kesehatan berpengalaman memberikan pelayanan kesehatan kepada pasien selama dirawat di RS, $65,7 \%$ terpapar dengan produk darah, $45 \%$ melakukan prosedur cuci tangan, $25,7 \%$ sering meggunakan peralatan kesehatan, $14,3 \%$ tenaga kesehatan belum melakukan imunisasi Hep B, dan 37,1\% telah mengikuti pelatihan cuci tangan dan SKP.

Berdasarkan ketiga hasil penelitian tersebut menunjukkan bahwa sistem manajemen risiko dan pelayanan kesehatan yang tepat dapat memberikan pengaruh positif terhadap optimalisasi penerapan SKP. Kelengkapan fasilitas, dan staff yang terlatih akan mendukung sosialisasi dan kemudahan dalam penerapan SKP di RS.

\section{Pengetahuan, Sikap, dan Tindakan}

Terdapat dua penelitian yang berhubungan dengan aspek pengetahuan, sikap, dan tindakan. Penelitian pertama HB Gebru, et all, 2013 ${ }^{[9]}$ bertujuan untuk mengidentifikasi pengetahuan, sikap, dan tindakan keselamatan dalam melakukan injeksi yang dilakukan oleh tenaga kesehatan professional. Hasil penelitian tersebut menunjukkan bahwa dari 189 tenaga kesehatan, diperoleh data hanya 161 orang (85\%) yang mempunyai pengetahuan tentang tindakan injeksi yang tidak aman atau berisiko, 135 orang
(71\%) telah mengetahui cara pemberian obat dengan single dose. Data lain menunjukkan bahwa 149 orang (79\%) mengetahui bahwa ketidaktepatan dalam pemberian obat dapat menyebabkan infeksi. 50 (26\%) dan 80 (42\%) dari tenaga kesehatan professional tidak menerapkan teknik aseptic dan tidak mendapatkan pelatihan terhadap prosedur keamanan injeksi. $40 \%$ dari tenaga kesehatan mengalami insinden needle stick injury.

Penelitian kedua, Bernadetta, et all. 2015 ${ }^{[10]}$ bertujuan untuk mengetahui hubungan pengetahuan perawat tentang SKP dengan menerapkan SPO SKP di Rumah Sakit Panti Waluya Sawahan Malang. Hasil penelitian menunjukkan terdapat hubungan yang signifikan (bermakna) antara pengetahuan perawat di RSPW dengan pelaksanaan KPRS pada pasien berdasarkan hasil uji spearman diperoleh nilai korelasi sebesar 0.420 dengan signifikansi sebesar $0.001 \quad(\mathrm{p}<0.05)$. Sebagian besar 49 responden $(81,7 \%)$ mempunyai pengetahuan yang cukup. Lebih dari separuh responden $(68,3 \%)$ masih kurang dalam melaksanakan prosedur KPRS.

Dalam hal ini sangat diperlukan pengetahuan, sikap, dan tindakan tenaga kesehatan yang baik untuk menghindari terjadinya kesalahan atau malpraktik dalam pemberian pelayanan kesehatan. Kecakapan dan ketepatan tindakan staff akan mendukung tercapainya optimalisasi penerapan SKP yang dapat meningkatkan kualitas pelayanan kesehatan.

\section{Analisis Situasi dan Kondisi \\ Lingkungan Kerja}

Penelitian Marcia Kirwan et all, 2012[11] bertujuan untuk mengetahui hubungan antara lingkungan kerja perawat terhadap penerapan SKP. Hasil penelitian tersebut menunjukkan bahwa beban kerja perawat di setiap ruangan dan tingkat pendidikan perawat dalam suatu lingkungan kerja berpengaruh signifikan terhadap penerapan SKP. Prosentase pengaruhnya sebagai berikut beban kerja (76\%) dan tingkat pendidikan (51\%). Dalam hal ini 
menunjukkan bahwa lingkungan kerja yang positif dengan perhitungan beban kerja sesuai dengan SDM dan tingkat pendidikan staff setingkat sarjana dapat mendukung optimalisasi penerapan SKP

\section{Durasi Jam Kerja Perawat}

Penelitian Yinghui Wu, et all, 2013 ${ }^{[12]}$ bertujuan untuk mengetahui pengaruh jam kerja perawat terhadap sasaran keselamatan pasien. Hasil penelitian ini menunjukkan data sebagai berikut, responden perawat dibagi dalam tiga grup berdasarkan durasi jam kerja per minggu yaitu < 40 jam, 40-60 jam, dan > 60 jam. Semakin lama durasi jam kerja perawat semakin berisiko terhadap rendahnya penerapan budaya SKP. Dalam hal ini efektivitas jam kerja dapat berpengaruh terhadap kualitas kinerja perawat sehingga kinerja yang baik akan mendukung penerapan SKP secara maksimal.

\section{Program Mentoring}

Penelitian Devi Nurmalia, et all. 2013 ${ }^{[13]}$ bertujuan untuk mengetahui pengaruh program mentoring terhadap penerapan budaya keselamatan pasien di ruang rawat inap di salah satu rumah sakit swasta di Semarang. Hasil menunjukkan terdapat pengaruh antara penerapan budaya kelompok kontrol dengan kelompok intervensi sesudah progam mentoring $(p=0.056, x 2=4.5 \alpha=0.1)$ dan RR 2.5. Hasil analisis menunjukkan bahwa kelompok yang tidak mendapatkan program mentoring akan beresiko mengalami penurunan dalam penerapan budaya keselamatan pasien sebesar 2.5 kali lebih besar dibandingkan kelompok yang mendapatkan program mentoring keperawatan.

Penelitian menunjukkan metode baru dalam melakukan optimalisasi penerapan SKP yaitu dengan mentoring. Dalam pembahasan melibatkan asas dan teori 4 dimensi yaitu dimensi keterbukaan, keadilan, pelaporan, dan pembelajaran Implikasi bagi pelayanan dan pendidikan keperawatan untuk mengembangkan meotode pengarahan sesuai dengan kebutuhan perawat di rumah sakit.

\section{Supervisi Keperawatan, dan Evaluasi Penerapan SKP}

Terdapat tiga penelitian yang menunjukkan pengaruh supervisi keperawatan dan evaluasi SKP. Pertama penelitian Suparna et all, 2015 $5^{[14]}$ yang bertujuan untuk mengetahui evaluasi penerapan patient safety risiko jatuh unit gawat darurat di Rumah Sakit Panti Rini Kalasan Sleman. Hasil penelitian adalah penerapan patient safety risiko jatuh berdasarkan SPO aspek yang dilaksanakan $100 \%$ yaitu penulisan pada dokumentasi, sedangkan $50 \%$ pengkajian risiko jatuh, aspek pada pemasangan tanda risiko jatuh, didapat keterlaksanaannya hanya $51 \%$.

Kedua, penelitian Ari Rasdini, et all, 2015 $5^{[15]}$ untuk mengetahui hubungan antara supervisi pelayanan keperawatan dengan penerapan budaya keselamatan pasien di RSUP Sanglah Denpasar. Hasil penelitian menunjukkan bahwa ada hubungan signifikan dan berkekuatan sedang antara supervisi pelayanan keperawatan (normatif, formatif, dan restorarif) dengan penerapan budaya SKP oleh perawat pelaksana $(\mathrm{p}=0.000)$.

Ketiga, penelitian oleh Surahmat, et all. $(2018)^{[16]}$ yang bertujuan untuk mengetahui hubungan supervisi dengan implementasi sasaran keselamatan pasien di rumah sakit. Hasil penelitian menyebutkan terdapat hubungan yang signifikan $p=0,041$. Supervisi sangat diperlukan untuk mengetahui penerapan SKP.

Dalam hal ini supervisi keperawatan dan evaluasi SKP memberikan dampak positif terhadap penerapan SKP di rumah sakit. Supervisi keperawatan merupakan bentuk pengawasan dan pendampingan terhadap tindakan yang dilakukan oleh perawat. Pada periode tertentu dilakukan evaluasi yang bertujuan untuk mengetahui ketercapaian penerapan SKP sehingga jika ada aspek yang belum terpenuhi bisa dilakukan strategi yang lebih baik agar penerapan SKP bisa berjalan dengan baik untuk meningkatkan kualitas pelayanan kesehatan di rumah sakit. 


\section{IMLIKASI KEPERAWATAN}

Implikasi dari hasil literature review ini diharapkan diharapkan dapat memberikan dukungan positif di rumah sakit untuk menerapkan sistem manajemen dan pelayanan kesehatan yang prima dengan memaksimalkan penerapan SKP sehingga dapat menekan risiko terjadinya malpraktik atau kejadian tidak diinginkan. Peran perawat sangat penting dalam penerapan budaya keselamatan pasien sehingga perlunya pendalaman materi keselamatan pasien dalam pendidikan keperawatan.

Perlu adanya pengembangan penelitian lebih lanjut untuk mengidentifikasi faktor lain seperti etik dan dilemma serta factor emosional dan intelektual perawat yang dapat mempengaruhi penerapan SKP. Dalam proses penerapan SKP ini diharapkan ada kerjasama dan kolaborasi yang baik dari seluruh elemen rumah sakit agar bisa berjalan secara optimal dan memberikan dampak positif terhadap peningkatan kualitas pelayanan kesehatan.

\section{E. KESIMPULAN}

Literature review yang diperoleh dari 16 jurnal kesehatan menunjukkan berbagai faktor yang mempengaruhi optimalisasi penerapan SKP di rumah sakit. Faktor-faktor tersebut antara lain, aspek ekonomi, kepemimpinan, budaya, sistem pelayanan kesehatan, pengetahuan, sikap, dan tindakan tenaga professional, analisis situasi dan kondisi tempat kerja, sistem manajemen risiko, durasi jam kerja perawat, program mentoring, supervisi keperawatan, dan evaluasi penerapan SKP. Sedangkan parameter yang digunakan untuk mengukur penerapan SKP diperoleh datanya dari instrument kuesioner, lembar observasi checklist, dan lembar interview. Jenis instrument yang sering digunakan yaitu The Practice Environmental Scale of the Nursing Work Index (PES-NWI) dan The Hospital Survey of Patient Safety Culture.

Fenomena yang muncul serta hasil penelitiaan dari 16 jurnal tersebut mengindikasikan bahwa budaya keselamatan pasien dalam pelayanan kesehatan di rumah sakit memerlukan perhatian khusus dalam pelaksanaannya. Optimalisasi faktor-faktor yang mempengaruhi efektivitas penerapan SKP dapat meningkatkan kualitas penerapan SKP dengan baik sehingga dapat meningkatkan kualitas pelayanan kesehatan di rumah sakit.

\section{DAFTAR PUSTAKA}

[1] Depkes RI. (2011). Panduan Nasional Keselamatan Pasien Rumah Sakit. Jakarta: Depkes RI

[2] Burls A. What is critical appraisal? What is...? series of evidence-based medicine 2nd ed. Hayward Group Ltd, Hayward Medical Communications Division; 2010 Feb [cited 2012 August 12]. Supported by Sanofi Aventis. Available from: URL: HYPERLINK

http://www.medicine.oc.ac.uk/bandolier/pa inres/download/whatis/whats_critical_appr aisal.pdf

[3] Colla, J.B., Bracken, A,C., Kinney, L.M and Weeks, W.B. (2005). Measuring Patient Safety Climate: a Review of Surveys. Qual. Saf. Health. Care. 14; $364-$ 366.

[4] Setiowati, D. (2013). Kepemimpinan efektif head nurse meningkatkan penerapan budaya keselamatan pasien oleh perawat pelaksana di RSUPN Dr. Cipto Mangunkusumo Jakarta / Dwi Setiowati, Allenidekania, Luknis Sabri. Sekolah Tinggi Ilmu Kesehatan Indonesia Maju. Jurusan Keperawatan; Fakultas Ilmu Komputer Universitas Indonesia; Fakultas Kesehatan Masyarakat Universitas Indonesia, 2013

[5] Great Ormond Street Hospital NHS Trust for Children. Critical appraisal of journal article. United Kingdom: NHS; 2011 [cited 2012 August 12]. Available from: URL: HYPERLINK

http://www.ucl.ac.uk/ich/services/library/tr aining_material/critical-appraisal

[6] Institute of Health Science (Oxford). Critical appraisal skill programme (CASP), making sense of evidence: 10 questions to help you make sense of reviews. England: 
Public Health Resources Unit; 2016 [cited 2012 August 12]. Available from: URL: HYPERLINK http://www.sph.nhs.uk/sphfiles/S.Reviews Appraisal Tool.pdf

[7] Oyourou, O.A \& Adeoti. (2013). P335: Situational analysis of patient safety national device and risk management to healthcare procedures in Ivory Coast. 2nd International Conference on Prevention and Infection Control (ICPIC 2013) Geneva, Switzerland. 25-28 June 2013

[8] Flaherty RJ. A simple method for evaluating the clinical literature. Fam Pract Manag 2014;11(5):47-52.

[9] Shaheen M. Evidence based medicine and critical appraisal: Physicians' mess. Egypt.mJ. Bronchol 2011;3(1):5-10.

[10] Crombie IK, Davies HT. What is metaanalysis? What is...? series of evidencebased medicine 2nd ed. Hayward Group Ltd, Hayward Medical Communications Division; 2011 Feb [cited 2012 August 12]. Supported by Sanofi Aventis. Available from: URL: HYPERLINK http://www.medicine.oc.ac.uk/bandolier/pa inres/download/whatis/meta_an.pdf

[11] Perera R, Heneghan C. Interpreting metaanalysis in systematic reviews. Evid. Based Med. 2011;13:67-9.

[12] Dept. of General Practice University of Glasgow. Critical appraisal checklist for a systematic review [cited 2012 August 12]. Available from URL: HYPERLINK http://www.gla.ac.uk/media_64047_en.pdf

[13] Nurmalia, D., Handiyani, H., Pujasari, H. (2013). Pengaruh Program Mentoring Terhadap Penerapan Budaya Keselamatan Pasien. Jurnal Managemen Keperawatan . Volume 1, No. 2, November 2013; 79-88

[14] Suparna \& Kurniawati, T. (2015). Evaluasi Penerapan Patient Safety Resiko Jatuh Unit Gawat Darurat di Rumah Sakit Panti Rini Kalasan Sleman. STIKES 'Aisyiyah Yogyakarta

[15] Rasdini, A.IGA., Wedri, N.M., Mega, IGA. (2015). Hubungan Antara Supervisi Pelayanan Keperawatan Dengan Penerapan Budaya Keselamatan Pasien Di RSUP Sanglah Denpasar. Jurnal Politeknik Kesehatan Denpasar.

[16] Surahmat, R; Neherta,N; \& Nurariati. (2018). Hubungan Supervisi dengan Implementasi Sasaran keselamatan Pasien di Rumah Sakit Muhammadiyah Palembang. Seminar Nasional Keperawatan. 